\title{
PRODUÇÃO DE ENZIMAS LIGNOCELULOLÍTICAS POR FERMENTAÇÃO EM ESTADO SÓLIDO DE RESÍDUOS AGROINDUSTRIAIS SOB AÇÃO DE FUNGO BASIDIOMICETO
}

\author{
B. FREIRE ${ }^{1}$, G. D. COELHO ${ }^{2}$, L. R. de F. CUNHA ${ }^{3}$, L. de S. C. OLIVEIRA ${ }^{4}$, P. M. S. ABREU \\ e R. CASEMIRO ${ }^{6}$ \\ ${ }^{1}$ Universidade Federal de Campina Grande, Departamento de Engenharia Química \\ ${ }^{2}$ Universidade Federal de Campina Grande \\ ${ }^{3}$ Universidade Federal de Campina Grande, Programa de Pós-Graduação em Engenharia de \\ Processos \\ ${ }^{4}$ Universidade Federal de Campina Grande \\ ${ }^{5}$ Universidade Federal de Campina Grande, Departamento de Engenharia Química \\ ${ }^{6}$ Universidade Federal de Campina Grande, Departamento de Engenharia Química \\ patimsam@hotmail.com
}

\begin{abstract}
RESUMO - Resíduos agroindustriais são materiais considerados viáveis para a bioconversão, são normalmente produzidos em grandes quantidades e descartados, potencializando os danos ambientais ao planeta. Nesse sentido, esse trabalho teve por objetivo produzir as enzimas lacase e endoglicanase por meio da fermentação em estado sólido (FES) sob ação do fungo Psilocybe castanella CCIBt 2781 inoculado em substratos a base de palha de milho verde suplementado com cana-de-açúcar e bagaço de coco verde suplementado com farinha de soja, nas proporções adequadas para se obter C/N 90, mediadores (óleo vegetal, Tween 80 e RBBR 2\%) e $70 \%$ de umidade a $28^{\circ} \mathrm{C}$, por 60 dias. Atividade de lacase foi determinada pela oxidação do ABTS; atividade de endoglicanase (CMCase) determinada por meio da dosagem dos açúcares redutores produzidos na degradação enzimática da carboximetilcelulose (CMC). O pico de atividade para lacase ocorreu no $30^{\circ}$ dia de fermentação $(113,0 \mathrm{U} / \mathrm{L})$, tendo coco como fonte de carbono e soja como fonte de nitrogênio. A maximização da produção de endoglicanase $(0,29 \mathrm{U} / \mathrm{g})$ ocorreu para o substrato a base de palha de milho e cana-de-açúcar, em 45 dias. Os resultados permitiram evidenciar que a bioconversão desses resíduos é uma forma viável de obtenção das enzimas lacase e endoglicanase.
\end{abstract}

\section{INTRODUÇÃO}

Em um momento no qual grandes mudanças na nossa maneira de pensar e viver são urgentemente necessárias, a Carta da Terra (documento que reúne os princípios fundamentais para a construção de uma sociedade global no século XXI) nos fornece uma nova base de pensamento e nos inspira a ter a visão ética que a proteção ambiental, os direitos humanos, o desenvolvimento humano equitativo e a paz são interdependentes e inseparáveis. O meio ambiente global com seus recursos finitos é uma preocupação comum de todas as pessoas. A proteção da vitalidade, diversidade e beleza da Terra é um dever sagrado (Carta da Terra, 2000). 
No Brasil, as atividades agroindustriais e a indústria de alimentos produzem grande quantidade de subprodutos, tais como bagaços, farelos, palhas, cascas e sementes. Aplicá-los em bioprocessos é viável, tendo em vista o seu baixo valor agregado, a grande disponibilidade e a elevada concentração de nutrientes, que tem potencial de uso para conversão por microrganismos na obtenção de produtos de alto valor agregado, como enzimas. Basicamente, esses subprodutos são constituídos de compostos lignocelulósicos, os quais são os recursos renováveis mais abundantes na natureza, sendo esses, constituídos majoritariamente de celulose, hemicelulose e lignina (Castro; Pereira, 2010; Galembeck et al., 2009). Dentre os bioprocessos, a fermentação no estado sólido (FES) se destaca (Galembeck et al., 2009; Rossi et al., 2009), podendo ser definida como a deposição de microrganismos sobre partículas sólidas com a quantidade de água suficiente para o crescimento celular.

Os fungos basidiomicetos são muito utilizados na biodegradação de resíduos industriais devido a sua habilidade em produzir enzimas, tais como as fenoloxidases que são capazes de degradar e mineralizar compostos lignocelulolíticos, fenólicos e xenobióticos (Paz et al., 2010). Foi utilizado o basidiomiceto Psilocybe castanella CCIBt 2781 pertencente à coleção de culturas fúngicas da Coleção de Cultura do Instituto de Botânica (CCIBt) de São Paulo.

A lacase é uma glicoproteína polifenoloxidase que contém cobre no seu sítio ativo e catalisa a redução de $\mathrm{O}_{2}$ para água, com simultânea oxidação de substratos fenólicos. A catálise de substratos fenólicos e compostos modelos de lignina por lacase ocorrem via transferência de um elétron, conduzindo à geração de radicais fenoxila, que podem ser convertidos a quinonas (Leonowicz et al., 2001). A importância tecnológica das lacases é resultante da capacidade de catalisar a transformação de um grande número de compostos aromáticos fenólicos e não fenólicos (Durán et al., 2002). Entre as aplicações das lacases incluem-se: a deslignificação, a biorremediação, o clareamento de vinho (Mayer \& Staples, 2002) e sucos, melhoramento da panificação e a descoloração de corantes têxteis (Wesenberg et al., 2003), o tratamento de resíduos líquidos (Durán \& Esposito, 2000). Nos últimos anos, tem sido evidenciado o potencial das lacases para o desenvolvimento de biosensores e de cátodos de hidrogênio em células de combustível (Shleev et al., 2005, Couto \& Herrera, 2006).

Sendo os fungos, os principais microrganismos utilizados pela indústria na produção de enzimas, a degradação de materiais lignocelulósicos pode ser feita através do uso de microrganismos que produzem enzimas específicas que hidrolisam a celulose, resultando, no fim do bioprocesso, na molécula de glicose (Santos; Gouveia, 2009). A biodegradação da celulose é estimulada pelas enzimas celulolíticas, naturalmente, e as celulases livres são produzidas por fungos e bactérias aeróbicos (Sales et al., 2010; Basso et al., 2010). As enzimas celulolíticas se destacam no beneficiamento de produtos de indústrias têxteis, de papel, farmacêutica e alimentícia, dentre outras (Abdeshahian et al., 2011; Malik et al., 2010; Oberoi et al., 2010).

Este trabalho objetivou verificar a produção das enzimas lacase e endoglicanase (CMCase), por meio da FES dos resíduos lignocelulósicos a base de palha de milho verde suplementado com bagaço de cana-de-açúcar e bagaço da casca de coco verde suplementado com farinha de soja, sob ação do fungo Psilocybe castanella CCIBt 2781.

\section{MATERIAIS E MÉTODOS}

O basidiomiceto Psilocybe castanella CCIBt 2781, foi mantido a $4^{\circ} \mathrm{C}$ em meio ágar extrato 
de malte (MEA) 2\%. Após crescimento, as linhagens foram cultivadas em placas de Petri contendo MEA $2 \%$, incubadas a $25^{\circ} \mathrm{C}$ até que o micélio colonizasse $3 / 4$ da superfície da placa. Foi utilizado como inóculo $1 / 6$ do micélio fúngico cultivado da placa, para cada frasco contendo substrato sólido.

As fermentações foram realizadas em duplicata, em frascos de vidro de $200 \mathrm{~mL}$ contendo 20 g de substrato, previamente umidificado e autoclavado a $121^{\circ} \mathrm{C}$ por $1 \mathrm{~h}$. Como substratos utilizouse palha de milho verde suplementado com cana-de-açúcar e bagaço de coco verde suplementado com farinha de soja, na $\mathrm{C} / \mathrm{N}$ 90. A umidade inicial do meio foi ajustada para $70 \%$, base úmida, pela adição de um volume definido de água destilada, determinado através do balanço de massa. De acordo o planejamento experimental, a cada frasco foram adicionadas diferentes quantidades de mediadores (emulsão de óleo vegetal $(1 \mathrm{~mL})$, Tween $80(0,1 \mathrm{~mL})$ e Azul Brilhante de Remazol $\mathrm{R}(\mathrm{RBBR}) 2 \%(1 \mathrm{~mL}))$ e $1 / 6$ de inóculo fúngico.

Os experimentos foram conduzidos à temperatura $\left(28^{\circ} \mathrm{C}\right)$ e umidade controladas $(70 \%)$, em câmara incubadora (modelo MA1415/780 Marconi) e em diferentes tempos de fermentações (15, 30, 45, e 60 dias). Finalizado o tempo de fermentação, a cada frasco foram adicionados $60 \mathrm{~mL}$ de solução tampão de acetato de sódio com pH 4,8 a $50 \mathrm{mM}$. Essa suspensão foi agitada manualmente durante 5 minutos, seguida de agitação a $120 \mathrm{rpm}$ por $1 \mathrm{~h}$ em incubadora com agitação orbital (modelo MA420 Marconi). A suspensão contendo o extrato enzimático bruto foi extraída por meio da filtração em papel de filtro qualitativo.

A atividade da lacase foi determinada pela oxidação do ácido 2,2'-azino-bis(3etilbenzotiazolina-6-sulfônico) (ABTS). A mistura foi utilizada usando $0,75 \mathrm{~mL}$ de tampão citratofosfato a $50 \mathrm{mM}(\mathrm{pH} 4,0), 0,15 \mathrm{~mL}$ de água Milli-Q® Ultrapure da marca Millipore, $0,3 \mathrm{~mL}$ de uma solução de ABTS a $5 \mathrm{mM}$ e 1,8 mL do extrato enzimático. Com a adição do ABTS a reação foi iniciada e sua oxidação, acompanhada pelo aumento da absorbância a $420 \mathrm{~nm}$ no espectrofotômetro Bel Photonics 2000 UV. Uma unidade de atividade enzimática (U) foi definida como a quantidade de enzima capaz de oxidar $1 \mu \mathrm{mol}$ de ABTS por minuto, sendo a atividade enzimática aqui expressa em U/L.

A atividade cinética da enzima endoglicanase, também chamada de carboximetilcelulase (CMCase), foi determinada por meio da dosagem dos açúcares redutores produzidos na degradação enzimática da carboximetilcelulose (CMC) a $1 \%$ m/v diluído em solução tampão de acetato de sódio com o pH 5,0 a $50 \mathrm{mM}$ e sua quantificação ocorreu por meio do método do ácido dinitrosalicílico (DNS) (Miller, 1959). Em três tubos de ensaio foram adicionados: 1,0 mL de solução tampão de acetato de sódio, $1,0 \mathrm{~mL}$ de extrato enzimático bruto e $1,0 \mathrm{~mL}$ de CMC (1\% $\mathrm{m} / \mathrm{v}$ ); controle da reação - 1,0 $\mathrm{mL}$ do mesmo tampão e 1,0 mL de extrato enzimático; branco da reação - 1,0 mL de água destilada e 1,0 mL de DNS. A reação foi interrompida com a adição de 1,0 mL DNS. Os tubos foram submergidos em banho-maria (Solab) por 60 minutos, após esse tempo foram adicionados $1,0 \mathrm{~mL}$ de água destilada e, posteriormente, foi efetuada a medição de absorbância a $540 \mathrm{~nm}$. Essa quantificação foi repetida três vezes para cada unidade de tratamento. A unidade de atividade enzimática (U) foi definida como a quantidade de enzima capaz de liberar $1 \mu \mathrm{mol}$ de açúcares redutores por minuto a $50^{\circ} \mathrm{C}$, sendo a atividade enzimática expressa em $\mathrm{U} / \mathrm{g}$.

\section{RESULTADOS E DISCUSSÃO}

Nas Tabelas 1 e 2 são apresentados os resultados obtidos para o crescimento microbiano, 
determinado por observação visual, de acordo com o padrão adaptado da ASTM G21-90 (1990). Os resultados estão organizados em função de cada tratamento e do tempo de fermentação, na temperatura de $28^{\circ} \mathrm{C}$. Como pode ser observado, o fungo apresentou crescimento micelial significativo já nos primeiros 15 dias de incubação, para os dois substratos utilizados. Silva (2009), estudando a biodegradação de polietileno tereftalato (PET) sob ação da linhagem de espécies de Pleurotus spp. nas misturas de farelo de arroz e farelo de trigo, encontrou crescimento micelial significativo após 14 dias de incubação.

Na Tabela 1, observa-se a variação do crescimento microbiano para o substrato a base de palha de milho e cana-de-açúcar. Verificou-se que nos primeiros 15 dias houve crescimento, havendo um acréscimo no desenvolvimento micelial nos frascos contendo os mediadores RBBR, Tween 80 e RBBR. Aos 30 dias a maior colonização da superfície foi observada sob ação do Tween 80 e RBBR, e aos 45 dias em todos os frascos contendo RBBR, demostrando uma expressiva descoloração do RBBR, mantendo-se até os 60 dias. Nesse sentido, pode-se dizer que houve influência da presença do corante sobre o aumento de biomassa de $P$. castanella.

Tabela 1 - Efeito dos mediadores sobre o crescimento microbiano durante a fermentação do resíduo de palha de milho e cana-de-açúcar à temperatura de $28^{\circ} \mathrm{C}$

\begin{tabular}{ccccc}
\hline MEDIADORES & 15 dias & 30 dias & 45 dias & 60 dias \\
\hline Controle & ++ & ++ & ++ & + \\
Óleo & + & ++ & ++ & + \\
Tween 80 & + & ++ & ++ & ++ \\
Óleo e Tween 80 & ++ & ++ & + & ++ \\
RBBR & +++ & ++ & +++ & ++ \\
Óleo e RBBR & + & + & +++ & +++ \\
Tween 80 e RBBR & +++ & +++ & +++ & +++ \\
Óleo, Tween 80 e RBBR & - & ++ & +++ & +++ \\
\hline
\end{tabular}

Legenda: (-) ausência de crescimento; (+) pouco crescimento com turvação de pequenos fragmentos de micélio lançados no meio; $(++)$ moderado crescimento com surgimento de "pellet" fino na superfície do meio; $(+++)$ ótimo crescimento de massa micelial da metade a todo frasco.

$\mathrm{Na}$ Tabela 2, observa-se a variação do crescimento para o substrato a base de bagaço de coco verde e farinha de soja. Observou-se nos primeiros 15 dias crescimento micelial, até que em 30 dias ocorreu sua colonização máxima, com posterior redução desse crescimento, notavelmente nos frascos contendo RBBR. Não foi detectada influência da presença do corante sobre o aumento de biomassa de $P$. castanella.

Tabela 2 - Efeito dos mediadores sobre o crescimento microbiano durante a fermentação do resíduo de bagaço de coco verde e farinha de soja à temperatura de $28^{\circ} \mathrm{C}$

\begin{tabular}{ccccc}
\hline MEDIADORES & 15 dias & 30 dias & 45 dias & 60 dias \\
\hline Controle & ++ & +++ & ++ & + \\
Óleo & ++ & +++ & ++ & +++ \\
Tween 80 & ++ & +++ & ++ & ++ \\
Óleo e Tween 80 & ++ & +++ & ++ & + \\
RBBR & ++ & +++ & + & + \\
Óleo e RBBR & ++ & +++ & + & + \\
Tween 80 e RBBR & ++ & +++ & + & +++ \\
Óleo, Tween 80 e RBBR & ++ & +++ & + & + \\
\hline
\end{tabular}

Legenda: (-) ausência de crescimento; (+) pouco crescimento com turvação de pequenos fragmentos de micélio lançados no meio; $(++)$ moderado crescimento com surgimento de "pellet" fino na superfície do meio; $(+++)$ ótimo crescimento de massa micelial da 
metade a todo frasco.

Nas Figuras 1 e 2 são apresentados os resultados obtidos para as atividades de lacase, determinada usando ABTS. Observa-se que a variação da atividade enzimática ocorreu em função do tempo de fermentação $\left(15,30,45\right.$ e 60 dias), à temperatura $\left(28^{\circ} \mathrm{C}\right)$ e umidade $(70 \%)$ constantes. A maior atividade enzimática de lacase com 113,0 U/L foi observada no $30^{\circ}$ dia, para o substrato a base de bagaço de coco verde suplementado com farinha de soja, sob ação de todos os mediadores, como pode ser observado na Figura 1. A máxima produção de atividade de lacase neste período, pode ser explicada pelo aumento de biomassa de P. castanella.

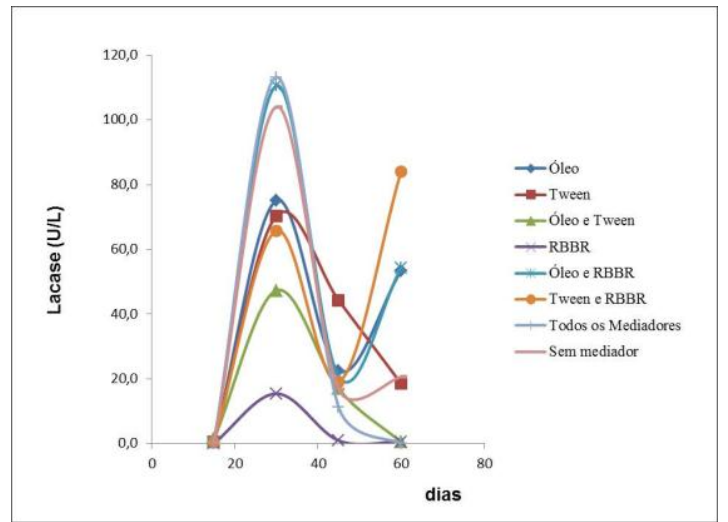

Figura 1 - Perfil cinético de produção de lacase em bagaço de coco verde e farinha de soja, na umidade inicial $70 \%$ a $28^{\circ} \mathrm{C}$.

Na Figura 2, para o substrato a base de milho e cana-de-açúcar, a máxima atividade de lacase $(98,25 \mathrm{U} / \mathrm{L})$ foi verificada aos 60 dias, sob ação de todos os mediadores, destacando-se a atividade de $65,24 \mathrm{U} / \mathrm{L}$ no $15^{\circ}$ dia, sob ação do óleo vegetal e Tween 80, e do RBBR. Nesta condição de cultivo, a adição de óleo vegetal e Tween 80, bem como RBBR, induziu a atividade de lacase, concordando com Yamanaka e Machado (2007). Trabalhando com meio de cultivo sintético, observaram que ao passo que na ausência do corante o fungo $P$. castanella foi capaz de produzir $25 \mathrm{UL}^{-1}$ em 15 dias de cultivo, na presença do RBBR houve produção de cerca de 100 $\mathrm{UL}^{-1}$ desta atividade enzimática aos 12 dias de cultivo.

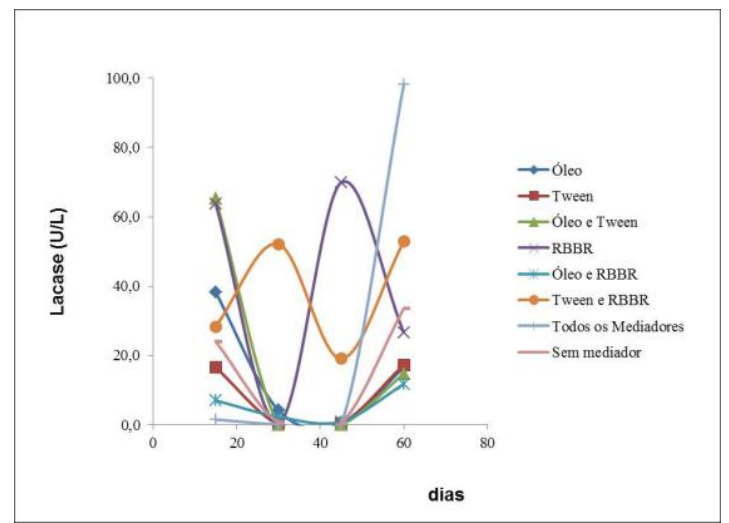

Figura 2 - Perfil cinético de produção de lacase em farelo de palha de milho verde e bagaço de cana-de-açúcar, na umidade inicial $70 \%$ a $28^{\circ} \mathrm{C}$. 
Na Figura 3, observa-se a variação da atividade de endoglicanase (CMCase) em função do tempo de fermentação. Observou-se que a maior atividade enzimática $(0,29 \mathrm{U} / \mathrm{g})$ ocorreu para o substrato a base de palha de milho verde e cana-de-açúcar, em 45 dias, sob a ação do RBBR, constatando-se que houve influência da presença do RBBR sobre a atividade de CMCase produzida por $P$. castanella. A máxima produção de atividade de CMCase pode ser explicada pelo o aumento de biomassa de $P$. castanella, como pode ser observado na Tabela 1 .

Rodríguez-Zúñiga et al. (2011), trabalhando com resíduo de cana-de-açúcar, obtiveram atividade de 0,3 U/g, utilizando Aspergillus Niger. Lins (2012), em estudo de produção de celulases com bagaço de pedúnculo do caju utilizando Trichoderma reesei LCB 48 e umidade inicial de $65 \%$, obteve atividade de $0,37 \mathrm{U} / \mathrm{g}$, valor de atividade inferior ao citado por Amorim (2010), que obteve em seus ensaios com bagaço de caju e $65 \%$ de umidade inicial, utilizando Trichoderma sp., atividade enzimática com $0,733 \mathrm{U} / \mathrm{g}$.

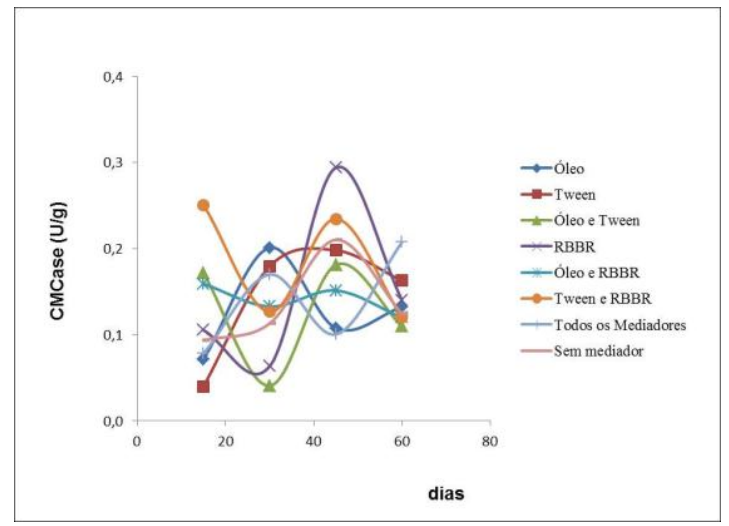

Figura 3 - Perfil cinético de produção de CMCase em palha de milho verde e bagaço de cana-de-açúcar, na umidade inicial $70 \%$ a $28^{\circ} \mathrm{C}$.

\section{CONCLUSÃO}

Em função dos dados obtidos, pode-se concluir que a bioconversão dos resíduos palha de milho verde suplementado com cana-de-açúcar e bagaço de coco verde, suplementado com farinha de soja sob fermentação em estado sólido com o auxílio do microrganismo Psilocybe castanella CCIBt 2781 é uma alternativa de obtenção da enzima lacase, apresentando-se o resíduo a base de milho e cana como uma matéria-prima viável para a produção de endoglicanase (CMCase). Os dados deste estudo permitiram também evidenciar a capacidade de $P$. castanella de degradar o corante Azul Brilhante Remazol R em meio de cultura definido, durante o intervalo de tempo de 45 dias, havendo total descoloração do corante após esse período. Houve influência da presença do RBBR sobre as atividades de lacase e endoglicanase, produzidas por P. castanella CCIBt 2781 nas condições avaliadas.

\section{REFERÊNCIAS}

ABDESHAHIAN, P.; SAMAT, N.; HAMID, A. A.; YUSOFF, W. M. W. Solid substrate fermentation for cellulose production using palm kernel cake as a renewable lignocellulosic source in packed-bed bioreactor. Biotechnol. and Bioprocess. Eng., Busan, v. 16, n. 2, p. 238-244, 2011.

AMORIM, B. C. Estudo da produção de celulases por fermentação semi-sólida em bagaço de caju 
(Anarcadium occidentalle L.) utilizando o microrganismo Trichoderma sp. Dissertação (Mestrado). Universidade Federal de Campina Grande. Campina Grande, 2010.

BASSO, T. P.; GALLO, C. R.; BASSO, L. C. Atividade celulolítica de fungos isolados de bagaço de cana-de-açúcar e madeira em decomposição. Pesquisa Agropecuária Brasileira, Brasília, v. 45, n. 11, p. 1282-1289, 2010.

CARTA DA TERRA, 2000.

CASTRO, A. M.; PEREIRA, N. Produção, propriedades e aplicação de celulases na hidrólise de resíduos agroindustriais. Química Nova, São Paulo, v. 33, n. 1, p. 181-188, 2010.

COUTO, S. R.; HERRERA, J. L. T. Industrial and biotechnological applications of laccases: a review. Biotechnol. Adv., v. 24, p. 500-513, 2006.

DURÁN, N.; ESPOSITO, E. Potential applications of oxidative enzymes and henoloxidase like compounds in wastewater and soil treatment: a review Applied Catalysis B. Environ., v. 28, p. 8399, 2000.

DURÁN, N.; ROSA, M. A.; D’ANNIBALE, A.; GIANFREDA, L. Applications of laccases and tyrosinases (phenoloxidases) immobilized on different supports: a review. Enzyme Microb. Technol., New York, v. 31, p. 907-931, 2002.

GALEMBECK, F.; BARBOSA, C. A. S.; SOUSA, R. A. Aproveitamento sustentável de biomassa e de recursos naturais na inovação química. São Paulo: Química Nova, 2009.

LEONOWICZ, A.; CHO, N. S.; LUTEREK, J.; WILKOLAZKA, A.; WOJTAS-WASILEWSKA, M.; MATUSZEWSKA, A.; HOFRICHTER, M.; WESENBERG, D.; ROGALSKI, J. Fungal laccase: properties and activity on lignin. J. Basic Microbiol., Berlin, v. 41, p. 185-227, 2001.

LINS, S. A. da S. Produção de celulases por fermentação semi-sólida em bagaço de pedúnculo do caju utilizando Trichoderma reesei LCB 48. Dissertação (Mestrado). Universidade Federal de Campina Grande. Campina Grande, 2012.

MALIK, S. K.; MUKHTAR, H.; FAROOQI, A. A.; IKRAM-UL-HAQ. Optimization of process parameters for the biosynthesis of cellulases by Trichoderma viride, Pakistan J. Botany, v. 42, n. 6, p. 4243-4251, 2010.

MAYER, A. M.; STAPLES, R. C. Laccase: new functions for an old enzyme. Review. Phytochem. v. 60, p. 551-565, 2002.

MILLER, G. L. Use of dinitrosalicylic acid reagent for determination of reducing sugar. Anal. Chem., Washington, v. 31, n. 3, p. 426-428, 1959.

OBEROI, H. S. et al. Production of cellulases through solid state fermentation using kinnow pulp as a major substrate. Food Bioprocess Technol., Dublin, v. 3, n. 4, p. 528-536, 2010.

PAZ, E. S. L. da; FONSECA, A. P. G. da; FREITAS, L. R.; GUARANÁ, C. F. R.; JÚNIOR, F. B. da P. Isolamento e avaliação da atividade fenoloxidase de Basidiomycetes coletados em área de Mata Atlântica - PE. CIENTEC - Revista de Ciência, Tecnologia e Humanidades do IFPE - Ano II, n. 1, 2010.

RODRÍGUEZ-ZÚÑIGA, U. F.; FARINAS, C. S.; NETO, V. B.; COURI, S.; CRESTANA, S. Produção de celulases por Aspergillus niger por fermentação em estado sólido. Pesquisa Agropecuária Brasileira, Brasília, v. 46, n. 8, p. 912-919, 2011. 
ROSSI, S. C.; VANDENBERGHE, L. P. S.; PEREIRA, B. M. P.; GAGO, F. D.; RIZZOLO, J. A.; PANDEY, A.; SOCCOL, C. R.; MEDEIROS, A. B. P. Improving fruity aroma production by fungi in SSF using citric pulp. Food Res. Int., v. 42, p. 484-486, 2009.

SANTOS, J. R. A.; GOUVEIA, E. R. Produção de bioetanol de bagaço de cana-de-açúcar. Revista Brasileira de Produtos Agroindustriais, Campina Grande, v. 11, n. 1, p. 27-33, 2009.

SHLEEV, S.; JAROSZ-WILKOLAZKA, A.; KHALUNINA, A.; MOROZOVA, O.; YAROPOLOV, A.; RUZGAS, T.; GORTON, L. Direct electron transfer reactions of laccases from different origins on carbon electrodes. Bioelectrochem., v. 67, p. 115-124, 2005.

SALES, M. R.; MOURA, R. B. de; PORTO, T. S.; MACEDO, G. R. de; PORTO, A. L. F. Variáveis que influenciam a produção de celulases e xilanases por espécies de Aspergillus. Pesquisa Agropecuária Brasileira, Brasília, v. 45, n. 11, p. 1290-1296, 2010.

SILVA, K. R. I. da; Biodegradação de polietileno tereftalato (PET) por fungos ligninolíticos. Dissertação (Mestrado). Campinas, SP. 2009.

WESENBERG, D, KYRIAKIDES, I.; AGATHOS, S. White-rot fungi and their enzymes for the treatment of industrial dye effluents. Biotechnol., v. 22, p. 161-187, 2003.

YAMANAKA, R.; MACHADO, K. M. G. Influência do corante Azul Brilhante de Remazol R sobre o sistema enzimático ligninolítico de Psilocybe castanella CCB444 em meio de cultivo sintético. Revista Brasileira de Biociências, Porto Alegre, v. 5, supl. 2, p. 1119-1121, 2007. 